\title{
Interstitial Carbonic Anhydrase (CA) Activity in Brain Is Attributable to Membrane-Bound CA Type IV
}

\author{
Chi-Kun Tong, ${ }^{1}$ Luc P. Brion, ${ }^{3}$ Carlos Suarez, ${ }^{3}$ and Mitchell Chesler ${ }^{1,2}$ \\ Departments of ${ }^{1}$ Physiology and Neuroscience and ${ }^{2}$ Neurosurgery, New York University School of Medicine, New York, \\ New York 10016, and ${ }^{3}$ Department of Pediatrics, Albert Einstein College of Medicine, Bronx, New York 10461
}

\begin{abstract}
We tested the hypothesis that extracellular membrane-bound carbonic anhydrase (CA) type IV is responsible for the regulation of interstitial $\mathrm{pH}\left(\mathrm{pH}_{\mathrm{o}}\right)$ transients in brain. Rat hippocampal slices were incubated in phosphatidylinositol-specific phospholipase $\mathrm{C}$ (PI-PLC), which cleaves the link of CA IV to the external face of plasma membranes. Then evoked alkaline $\mathrm{pH}_{\mathrm{o}}$ shifts were studied in a recording chamber, using $\mathrm{pH}$ microelectrodes. Incubation fluid was saved for later analysis. The ability to buffer a rapid alkaline load was reduced markedly in PI-PLC-treated tissue as compared with adjacent, paired control slices. The effect of benzolamide (a poorly permeant $\mathrm{CA}$ inhibitor) on evoked $\mathrm{pH}_{\mathrm{o}}$ shifts was diminished greatly in the PI-PLC-treated tissue, consistent with the washout of interstitial CA. Treatment of the incubation fluid with SDS abolished nearly all of the CA activity in
\end{abstract}

fluid from controls, whereas an SDS-insensitive component remained in the fluid from PI-PLC-treated slices. These data suggested that CA type II (which is blocked by SDS) leaked from injured glial cells in both slice preparations, whereas CA type IV (which is insensitive to SDS) was liberated selectively into the fluid from PI-PLC-treated tissue. Western blot analysis was consistent with this interpretation, demonstrating a predominance of CA IV in the incubation fluid from PI-PLC-treated tissue and variable amounts of CA II in fluid from PI-PLC-treated and control slices. These results demonstrate that interstitial CA activity brain is attributable principally to membrane-bound CA IV.

Key words: hippocampal slice; carbonic anhydrase; benzolamide; phosphatidylinositol-glycan link; extracellular $\mathrm{pH}$; alkaline shift
Rapid shifts in interstitial $\mathrm{pH}\left(\mathrm{pH}_{\mathrm{o}}\right)$ are known to accompany synchronous neural discharge and spreading depression (Chesler, 1990; Chesler and Kaila, 1992). These endogenous $\mathrm{pH}_{\mathrm{o}}$ changes can influence neuronal function via their effect on ligand and ion-gated channels (Traynelis, 1998). The degree of influence will depend on the size, speed, and spread of these $\mathrm{pH}_{\mathrm{o}}$ changes. The key factor governing these variables is the buffering capacity of the extracellular fluid.

Almost all of the $\mathrm{pH}$ buffering capacity of the ECF is provided by the carbonic acid system according to the reactions:

$\mathrm{CO}_{2}+\mathrm{H}_{2} \mathrm{O}=\mathrm{H}_{2} \mathrm{CO}_{3}=\mathrm{HCO}_{3}{ }^{-}+\mathrm{H}^{+}$.

Given an extracellular bicarbonate concentration of $26 \mathrm{~mm}$, the buffering capacity of this system would be very high at equilibrium (Chesler, 1990). However, the attainment of equilibrium is slow, because the time constant for $\mathrm{CO}_{2}$ hydration is $\sim 20 \mathrm{sec}$ (Maren, 1967). To speed these reactions, biological systems use the enzyme carbonic anhydrase (CA), which catalyzes the reversible hydration of $\mathrm{CO}_{2}$ (Maren, 1967; Tashian, 1989).

The bulk of brain CA resides within oligodendrocytes and astrocytes as the CA II isoform (Cammer, 1984; Cammer and Tansey, 1988). To catalyze extracellular buffering rapidly, however, CA would have to be present in the interstitial compartment. A role for $\mathrm{CA}$ in the control of extracellular buffering was suggested by the in vivo studies of Kraig and colleagues (1983), who found that superfusion of acetazolamide caused a marked amplification of alkaline $\mathrm{pH}_{\mathrm{o}}$ transients in rat cerebellum. Later studies in brain slices demonstrated similar amplification by using CA inhibitors that do not penetrate cell membranes readily (Chen and Chesler, 1992a,b; Kaila et al., 1992). These results indicated that the targeted CA activity had an extracellular location. The enlargement of the

\footnotetext{
Received June 5, 2000; revised Aug. 21, 2000; accepted Aug. 24, 2000.

This work was supported by National Institute of Neurological Diseases and Stroke Grants NS32123 and NS34115 and American Heart Association Grant-in-Aid 9650445 N. We thank Dr. Wendy Cammer for advice throughout this study. Drs. Yu Liang and Yimi Amarillo provided technical assistance.

Correspondence should be addressed to Dr. Mitchell Chesler, Department of Physiology and Neuroscience, New York University School of Medicine, 550 First Avenue, New York, NY 10016. E-mail: mitch.chesler@med.nyu.edu.

Copyright (C) 2000 Society for Neuroscience $0270-6474 / 00 / 208247-07 \$ 15.00 / 0$
}

alkalization therefore has been explained by the slowing of $\mathrm{CO}_{2}$ hydration, which impedes the replenishment of extracellular $\mathrm{H}^{+}$ (Chen and Chesler, 1992b).

A similar demonstration of extracellular CA activity was reported recently in hippocampal slices from mutant mice, which lack the expression of CA II (Tong et al., 2000). These studies suggested that a different isoform must be responsible for the catalysis of interstitial buffering. A number of tissues express an extracellular isoform of CA, denoted CA IV (Carter et al., 1990; Ghandour et al., 1992; Waheed et al., 1992b). CA IV is tethered to plasma membranes by a phosphatidylinositol linkage and, accordingly, can be liberated by phosphatidylinositol-specific phospholipase C (PIPLC; Zhu and Sly, 1990; Waheed et al., 1992b).

To determine whether CA IV was responsible for the buffering of $\mathrm{pH}_{\mathrm{o}}$ transients in brain, we incubated rat hippocampal slices in PI-PLC, studied the buffering properties of the treated tissue, and subsequently probed the incubation fluid for CA. Our results demonstrate that extracellular CA activity in brain is attributable mainly to membrane-bound CA type IV.

A portion of these results has been presented in abstract form (Tong et al., 1999).

\section{MATERIALS AND METHODS}

Preparation and treatment. All procedures were performed with the approval of the New York University School of Medicine Institutional Animal Care and Use Committee. Transverse rat hippocampal slices were prepared from anesthetized juvenile postnatal day 8-14 (P8-P14) Sprague Dawley rats of either sex. Slices were cut to a thickness of only $150 \mu \mathrm{m}$ to maximize the diff usion of phospholipase $\mathrm{C}$ into the interstitial space (see below). Tissue was incubated in artificial CSF ( $\mathrm{aCSF}$ ) at room temperature for at least $1 \mathrm{hr}$ before subsequent procedures. Normal aCSF contained (in mм) $124 \mathrm{NaCl}, 3.0 \mathrm{KCl}, 3.0 \mathrm{CaCl}_{2}, 1.5 \mathrm{MgCl}_{2}, 26 \mathrm{NaHCO}_{3}, 1.0 \mathrm{NaH}_{2} \mathrm{PO}_{4}$, and $10 \mathrm{D}$-glucose; it was gassed with $95 \% \mathrm{O}_{2} / 5 \% \mathrm{CO}_{2}$ to a nominal $\mathrm{pH}$ of 7.4. In experiments that used tetramethylammonium $\left(\mathrm{TMA}^{+}\right)$-selective microelectrodes, $1 \mathrm{~mm}$ TMA chloride was added to the aCSF

Hippocampal slices were transferred to either of two warmed $\left(32-34^{\circ} \mathrm{C}\right)$ incubation chambers containing $150 \mu \mathrm{l}$ of aCSF. The aCSF was preequilibrated with $95 \% \mathrm{O}_{2} / 5 \% \mathrm{CO}_{2}$ and also was gassed gently with the mixture (via a 30 gauge needle) throughout the incubation period. Humidified gas of the same composition was passed over the fluid to prevent evaporation. At the start of the experiment PI-PLC (Sigma, St. Louis, MO) was added to one of the chambers to a final concentration of 5-8 $\mathrm{U} / \mathrm{ml}$ incubation fluid. The fluid and slice in the adjacent chamber had no PI-PLC added, 
A

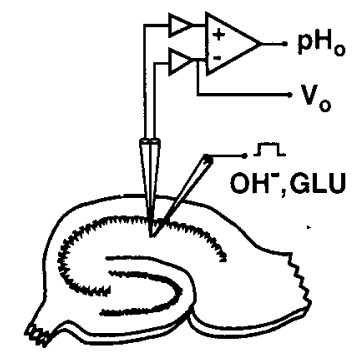

B

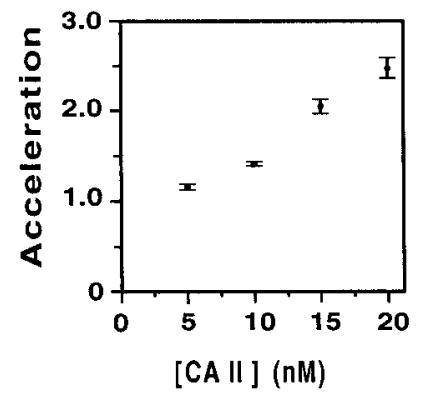

Figure 1. Recording arrangement and carbonic anhydrase assay. $A$, An ion-selective microelectrode and an iontophoresis pipette (for glutamate or $\mathrm{OH}^{-}$) were mounted on a dual micromanipulator and advanced 80-100 $\mu \mathrm{m}$ into stratum radiatum. $V_{\mathrm{o}}$ is the reference electrode potential. $B$, Acceleration of $\mathrm{CO}_{2}$ hydration by carbonic anhydrase type II $(C A I I)$ at concentrations from 5 to $20 \mathrm{nM}$.

serving as a control. After $1 \mathrm{hr}$ a second identical aliquot of PI-PLC was added to the experimental chamber. The total incubation time was 3-5 hr for the treated and untreated slices. Slices then were transferred to a submersion-style electrophysiological recording chamber superfused with aCSF maintained at $32^{\circ} \mathrm{C}$. The incubation fluids were collected and stored for either measurement of released CA activity or Western blot analysis.

Ion-selective microelectrodes. $\mathrm{pH}$ microelectrodes were fabricated by using a modification of the method of Lux (Lux, 1974; Chesler and Chan, 1988). In brief, a pair of bound thin-walled glass capillaries (AM Systems 6170 ) were heated, twisted $180^{\circ}$, and then drawn on a vertical pipette puller. The reference barrel and $\mathrm{pH}$-selective barrels were backfilled with $1 \mathrm{M} \mathrm{NaCl}$ and $150 \mathrm{~mm} \mathrm{NaCl} / 150 \mathrm{~mm} \mathrm{NaH}_{2} \mathrm{PO}_{4}, \mathrm{pH} 7.4$, respectively. The tips were broken to a diameter of 3-5 $\mu \mathrm{m}$, and the $\mathrm{pH}$ barrel was rendered hydrophobic by repeated suction and ejection of $4 \%$ trimethylchlorosilane in xylene. A column of proton-selective cocktail (Fluka 95291) was incorporated into the tip by suction. The slope response for extracellular $\mathrm{pH}$ electrodes was 57-59 mM per decade of change in $\mathrm{H}^{+}$activity. Doublebarreled microelectrodes selective for $\mathrm{TMA}^{+}$were constructed similarly, using the Corning exchanger 477317, followed by $150 \mathrm{mM}$ TMA chloride in the ion-selective barrel. The slope response for $\mathrm{TMA}^{+}$microelectrodes was $58-59 \mathrm{mV}$ per decade of change in TMA ${ }^{+}$activity. Potentials on the reference barrels were subtracted continuously from the voltage on the ion-selective barrels. The extracellular DC potential and the ion signal were displayed on a strip chart recorder.

Detection of interstitial CA activity in hippocampal slices. The presence of interstitial CA activity was detected with the carbonic anhydrase inhibitor benzolamide to amplify the extracellular alkaline transients (Chen and Chesler, 1992a). Benzolamide was a gift of Lederle Laboratories (Pearl River, NY). Because $\mathrm{HCO}_{3}{ }^{-}$efflux through $\mathrm{GABA}_{\mathrm{A}}$ receptors can cause an extracellular alkalization that is suppressed by benzolamide (Chen and Chesler, 1992a; Kaila et al., 1992), the generation of these $\mathrm{HCO}_{3}{ }^{-}$ dependent $\mathrm{pH}_{0}$ shifts can cause a mixed response to benzolamide and confound the comparison of interstitial CA activities (Taira et al., 1995) Therefore, $100 \mu \mathrm{M}$ picrotoxin (Sigma) was included in the aCSF to block the generation of $\mathrm{GABA}_{\mathrm{A}}$ receptor-mediated bicarbonate fluxes.

Interstitial alkaline shifts were elicited in PI-PLC-treated and control slices by two means. Endogenously generated alkaline transients were elicited by iontophoresis of glutamate (Chesler and Rice, 1991). Alkaline shifts induced by the activation of ionotropic glutamate receptors were generated by a net proton sink via activation of $\mathrm{Ca}^{2+}$-dependent (Paalasmaa et al., 1994; Smith et al., 1994) and $\mathrm{Ca}^{2+}$-independent mechanisms (Smith and Chesler, 1999) that have not been elucidated clearly. Imposed or "exogenous" alkalizations were created by the iontophoresis of $\mathrm{OH}^{-}$ (Huang et al., 1995). The $\mathrm{OH}^{-}$and glutamate micropipettes contained $0.1 \mathrm{~N} \mathrm{NaOH}$ or $250 \mathrm{~mm}$ sodium glutamate, $\mathrm{pH} 7.6$, respectively, and had tip diameters of $3-5 \mu \mathrm{m}$. To prevent blockage of the $\mathrm{NaOH}$-containing pipettes, we performed the ejection of $\mathrm{OH}^{-}$with aCSF containing $2 \mathrm{~mm}$ EGTA, devoid of $\mathrm{MgCl}_{2}$ and $\mathrm{CaCl}_{2}$. The $\mathrm{NaHCO}_{3}$ concentration of the aCSF was increased to $30 \mathrm{~mm}$ to counter the acidity of the EGTA. Ejection of $\mathrm{OH}^{-}$was accomplished with passage of -100 to $-400 \mathrm{nA}$ for $10 \mathrm{sec}$. A constant small forward bias of $0-50 \mathrm{nA}$ was used often to insure stability of the $\mathrm{OH}^{-}$-induced $\mathrm{pH}$ transients. Glutamate was iontophoresed with -400 to $-1000 \mathrm{nA}$ pulses on a $+50 \mathrm{nA}$ holding current.

The ejection micropipettes and a double-barreled $\mathrm{pH}$ microelectrode were mounted on a dual micromanipulator (Narishige MD-4, Tokyo, Japan) with a tip separation of $50-100 \mu \mathrm{m}$. The array was lowered into the stratum radiatum to a depth of $80-100 \mu \mathrm{m}$. Alkaline shifts were elicited alternately in PI-PLC-treated and in adjacent control slices placed in the same submersion chamber. The extracellular DC potential and ion signals were displayed on a strip chart recorder. A schematic of the experimental arrangement is shown in Figure $1 A$.

Interstitial volume comparisons. To determine whether treatment with PI-PLC altered the relative size of the interstitial space, we similarly lowered a $\mathrm{TMA}^{+}$iontophoresis pipette and a $\mathrm{TMA}^{+}$-selective microelectrode as an array into the stratum radiatum $(80-100 \mu \mathrm{m}$ depth, with a tip separation of 50-100 $\mu \mathrm{m})$. Iontophoretically evoked elevations of interstitial $\mathrm{TMA}^{+}$were elicited alternately in a PI-PLC-treated slice and in an adjacent control slice situated in the same submersion chamber. TMA ${ }^{+}$ was iontophoresed with currents of ${ }^{+} 60 \mathrm{nA}$ from a forward bias current of $+20 \mathrm{nA}$.

Collection of incubation fluid and analysis of CA activity. The incubation fluid for PI-PLC-treated and control slices (each sample totaling 300-500 $\mu l$, obtained from two to three slices) was concentrated and the bicarbonate removed, using a Microcon Centrif ugal Filter (YM-10). The filter had a $10 \mathrm{kDa}$ permselectivity to prevent the loss of CA while allowing the passage of bicarbonate. The sample fluid was centrif uged at $14,000 \times g$ for $25 \mathrm{~min}$ at room temperature until the volume was reduced to $2-5 \mu \mathrm{l}$. Deionized water $(100 \mu \mathrm{l})$ was added to the remaining sample, and the centrifugation was repeated to reduce the volume to 2-5 $\mu$ l again and eliminate the remaining bicarbonate. Before measurement of CA activity the sample was increased to $50 \mu \mathrm{l}$ by the addition of deionized water.

The measurement of CA activity in the fluid sample was performed with a method modified from Gros and colleagues (Bruns and Gros, 1991). A short glass vial with magnetic stir bar (flat bottom, $5 \mathrm{ml}$ total volume) was mounted in an ice water bath on a magnetic stir plate. $\mathrm{A} 95 \% \mathrm{O}_{2} / 5 \% \mathrm{CO}_{2}$ gas mixture was blown through the vial at a constant rate. $\mathrm{A} \mathrm{pH}$ indicator solution $\left(350 \mu \mathrm{l}\right.$ of $12.5 \mathrm{mg} / \mathrm{l}$ phenol red and $\left.2.6 \mathrm{~mm} \mathrm{NaHCO}{ }_{3}\right)$ and $50 \mu \mathrm{l}$ of sample fluid were added to the vial and mixed for at least $3 \mathrm{~min}$. In some experiments $0.2 \%$ SDS was included in the $50 \mu \mathrm{l}$ sample before its addition to the reaction vial. To avoid foaming, we guided the gas mixture over the surface of the solution.

The timed reaction was begun with the addition a buffer solution $(10 \mu \mathrm{l})$ containing $300 \mathrm{~mm} \mathrm{Na}_{2} \mathrm{CO}_{3}$ and $206 \mathrm{~mm} \mathrm{NaHCO}_{3}$, which raised the $\mathrm{pH}$ to a constant high value $(\sim 10.2)$ at time 0 . Because the solution was gassed constantly with $5 \% \mathrm{CO}_{2}$, the $\mathrm{pH}$ gradually fell because of the net hydration of $\mathrm{CO}_{2}$. The reaction with $\mathrm{CO}_{2}$ was timed to an end point at which the indicator turned abruptly from red to light yellow $(\mathrm{pH} \sim 7.3-7.4)$. The accuracy of the endpoint point determination was on the order of $1-2 \%$ of the total reaction time. The uncatalyzed reaction time (e.g., with pure water) was defined as $t_{\mathrm{o}}$. The catalysis of the reaction in the tested samples was given by the dimensionless acceleration factor $t_{\mathrm{o}} / t$.

The prepared samples accelerated the hydration reaction less than twofold, suggesting extremely low concentrations of CA. To compare results against a well characterized enzyme, we measured the reaction acceleration at concentrations of commercial CA II (Sigma) ranging from 5 to $20 \mathrm{nM}$ (Fig. $1 B$ ). Mean differences in acceleration were significant among $0,5,10,15$, and $20 \mathrm{nM}$ CA II as determined with ANOVA and the Bonferroni Multiple Comparisons Test.

Statistics were expressed as means with SE, with $n$ referring to the number of slices. Comparisons were made with a paired or unpaired two-tailed Student's $t$ test, as noted.

Western blots. Fresh samples of incubation fluid were kept in the refrigerator overnight. A cocktail of protease inhibitors was added during the incubation (Brion et al., 1997). The protease inhibitors included $1 \mathrm{~mm}$ phenylmethylsulfonyl fluoride [PMSF], $1 \mathrm{mM} O$-phenanthroline, $1 \mathrm{~mm}$ EDTA, and $1 \mu \mathrm{g} / \mathrm{ml}$ each of leupeptin, antipain, pepstatin, and aprotinin. After centrifugation of the incubation fluid sample, the pellet was solubilized in aCSF with $1 \%$ SDS for $30 \mathrm{~min}$; then the insoluble material was removed by a quick spin. Protein concentration was measured via the detergent-compatible modification of the Lowry assay (Bio-Rad, Hercules, CA). As positive standards we used recombinant human CA IV (secreted form, gift from W.S. Sly, St. Louis University, St. Louis, MO) (Waheed et al., 1996) or purified human CA II (Bio-Rad). Each standard sample (5-10 $\mu \mathrm{l}$ containing $10-15 \mu \mathrm{g}$ of protein, with $250 \mathrm{ng}$ of CA II or $50 \mathrm{ng}$ of CA IV) was run on reducing SDS-PAGE (Brion et al., 1994a) and transferred overnight into nitrocellulose membranes (Brion et al., 1997). All blocking and antisera incubations were done in PBS with $3 \%$ albumin and $0.1 \%$ Tween 20. After being blocked for $1 \mathrm{hr}$, the membrane was incubated for $2 \mathrm{hr}$ with a 1:2000 dilution of rabbit antiserum to mouse CA IV (gift from W. S. Sly) or a 1:5000 dilution of rabbit antiserum to mouse CA II (Cammer and Zhang, 1991). These antisera have been shown to be both specific and sensitive to mouse CA IV and CA II, respectively (Cammer and Zhang, 1991; Brion et al., 1997). Then the membrane was incubated for $1 \mathrm{hr}$ with a 1:5000 dilution of goat anti-rabbit IgG antibody conjugated to peroxidase. Bands were visualized with enhanced chemiluminescence (Renaissance, NEN Life Science Products, Boston, MA). Chemiluminescence-sensitive film (Hyperfilm ECL, Amersham, Arlington Heights, IL) was exposed to the membrane for $10-60$ sec. After scanning the film with an HP Scanner IICX, we measured the density of the bands, using two-dimensional analysis with the Zero-Dscan Image Analysis System (Scanalytics, Billerica, MA), and corrected the value for adjacent background. Optical densities (corrected to $10 \mu \mathrm{g}$ of protein) were reported with respect to that of the adjacent human CA standards (normalized to one).

\section{RESULTS}

\section{Interstitial buffering in hippocampal slices}

Interstitial buffering was compared in PI-PLC-treated and control hippocampal slices. A change in $\mathrm{pH}_{\mathrm{o}}$ was elicited exogenously by 
A

\section{$\mathrm{OH}^{-}$lontophoresis}

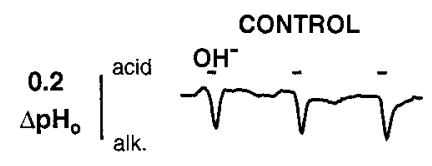

PI-PLC-TREATED

CONTROL<smiles>CCCCCCCCC</smiles><smiles>CCCCCC1CCCCC1C</smiles>

B

\section{Glutamate Iontophoresis}

CONTROL

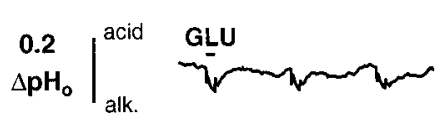

PI-PLC-TREATED

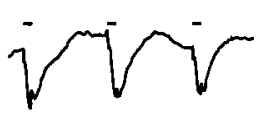

CONTROL

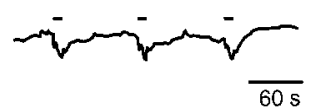

Figure 2. Interstitial alkaline transients were larger in slices that were treated with phosphatidylinositol-specific phospholipase $\mathrm{C}(P I-P L C)$. The microelectrode array was moved alternately between the control slice and the adjacent PI-PLCtreated slice, using constant current pulses. Acid and alkaline (alk) directions are indicated on the calibration bar. the local iontophoresis of $\mathrm{OH}^{-}$or endogenously by iontophoresis of glutamate. The microelectrode array, consisting of $\mathrm{pH}$-sensitive and iontophoresis electrodes, was moved alternately between the control slice and the adjacent PI-PLC-treated slice. Using the same iontophoretic current, we found that a striking increase in the size of the $\mathrm{OH}^{-}$-evoked responses was evident on moving to the PI-PLC-treated tissue (Fig. 2, top). In similar paired comparisons that used glutamate iontophoresis, the evoked alkaline shifts were again greater in the PI-PLC-treated tissue (Fig. 2, bottom).

The increase in the magnitude of the alkaline responses was not attributed to differences in the placement (e.g., depth) of the electrodes, because control-sized responses were elicited again when the array was returned to the untreated slice (Fig. 2, right panels). Results remained similar with repeated forays between control and treated tissue. Overall, the $\mathrm{OH}^{-}$and glutamateinduced alkaline shifts were both significantly greater in the PIPLC-treated tissue $(p<0.01$, paired $t$ test), with amplitudes increased over controls by 2.5 - and 1.7 -fold, respectively (Fig. 3).

The concentration of an iontophoresed substance in the interstitial space will depend on the extracellular volume fraction (Nicholson and Phillips, 1981). If the treatment with PI-PLC caused a decrease in extracellular volume, then the alkaline shifts would be enhanced correspondingly. To test whether there were marked differences in the extracellular volume fraction, we used a $\mathrm{TMA}^{+}$sensitive microelectrode mounted with a $\mathrm{TMA}^{+}$iontophoresis micropipette to probe for relative differences in interstitial volume (Dietzel et al., 1980). Evoked $\mathrm{TMA}^{+}$transients were recorded in alternate trials as the array was moved from control to PI-PLC-

\section{$\mathrm{OH}^{-}$lontophoresis GLU Iontophoresis}
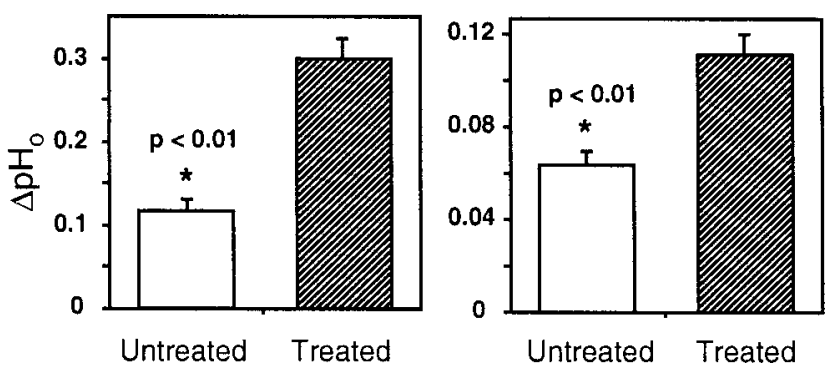

Figure 3. Mean alkaline shifts evoked in control versus PI-PLC-treated slices. With iontophoresis of either $\mathrm{OH}^{-}$or glutamate, the mean alkaline shifts were approximately doubled in the PI-PLC-treated slices, increasing over controls by $265 \pm 24$ and $179 \pm 17 \%$, respectively. Error bars represent SE. treated slices (Fig. 4). The baseline $\left[\mathrm{TMA}^{+}\right]_{\mathrm{o}}$ was elevated above that of the aCSF because of a constant forward bias current. There were no significant paired differences noted in baseline or peak $\left[\mathrm{TMA}^{+}\right]_{\mathrm{o}}$. The baseline averaged $1.82 \pm 0.14$ versus $1.85 \pm 0.07$ $\mathrm{mM}$, whereas the peak $\left[\mathrm{TMA}^{+}\right]_{\mathrm{o}}$ attained with iontophoresis averaged $3.33 \pm 0.36$ versus $3.31 \pm 0.18 \mathrm{~mm}$ in control versus PI-PLCtreated slices, respectively $(n=4)$.

\section{Effect of benzolamide in PI-PLC-treated versus control hippocampal slices}

Benzolamide is an acidic sulfonamide that does not penetrate cell membranes readily (Travis et al., 1964). It therefore has been used in numerous studies to block interstitial carbonic anhydrase activity

CONTROL

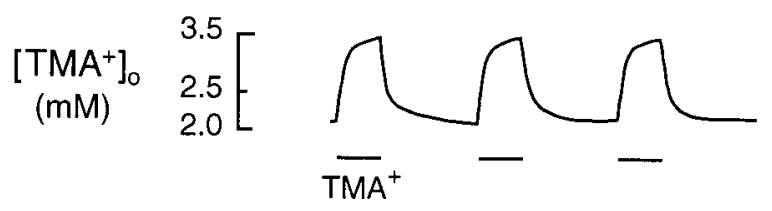

PI-PLC-TREATED

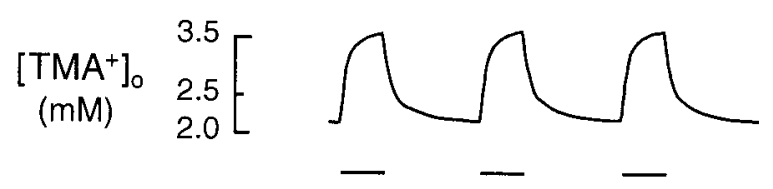

CONTROL

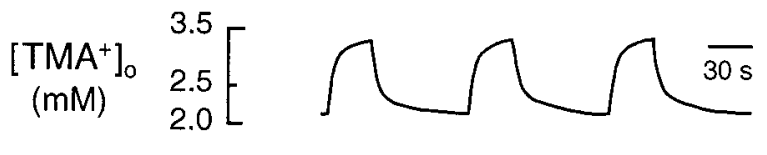

Figure 4. The extracellular volume fraction was unchanged in PI-PLCtreated tissue. Evoked increases in $\left[\mathrm{TMA}^{+}\right]$were no different in control versus PI-PLC-treated slices, indicating comparable volume fractions in the slices. 


\section{Untreated Slice}

\section{Control Benzolamide}

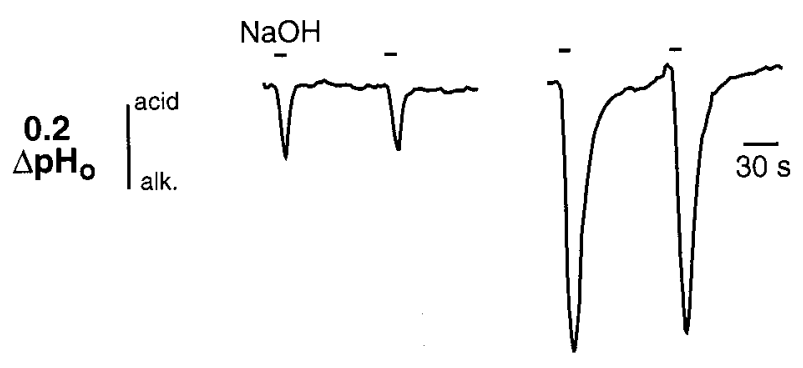

PI-PLC-Treated Slice

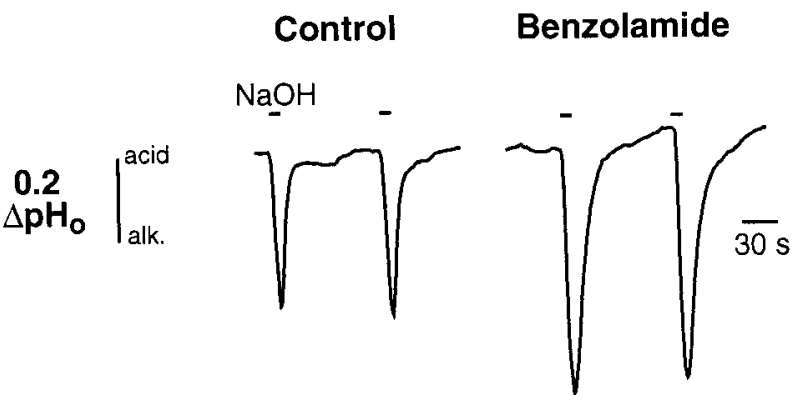

Figure 5. PI-PLC treatment precluded the effect of benzolamide on $\mathrm{OH}^{-}$evoked alkaline transients. Amplification of the alkaline shifts by benzolamide was reduced markedly in the PI-PLC-treated tissue. Experiments were performed in $0 \mathrm{Ca}^{2+} \mathrm{aCSF}$.

in brain (Chen and Chesler, 1992a; Kaila et al., 1992; Taira et al., 1995; Grichtchenko and Chesler, 1996). By slowing the rate of $\mathrm{H}^{+}$ buffering, inhibitors of interstitial CA cause a marked increase in the amplitude of $\mathrm{OH}^{-}$and glutamate-induced alkaline shifts (Chen and Chesler, 1992b). If treatment with PI-PLC resulted in the washout of interstitial CA activity, then the effect of benzolamide should be diminished, because the loss of CA would preclude the action of the CA inhibitor. We therefore compared the effect of benzolamide on $\mathrm{OH}^{-}$and glutamate-evoked alkaline shifts in control versus PI-PLC-treated slices.

In control slices the superfusion of $10 \mu \mathrm{M}$ benzolamide caused a striking increase in the amplitude of $\mathrm{OH}^{-}$-induced alkaline shifts, as reported previously (Chen and Chesler, 1992b; Huang et al., 1995). In adjacent PI-PLC-treated slices the alkaline transients were larger, and the increase caused by benzolamide was smaller (Fig. 5). Overall, benzolamide amplified the $\mathrm{OH}^{-}$-evoked alkaline shifts significantly less in PI-PLC-treated versus control tissue $(p<$ 0.001 , unpaired $t$ test), with increases of $62 \pm 45$ versus $332 \pm$ $157 \%$, respectively $(n=7)$.

Similar results were attained with glutamate iontophoresis (Fig. 6). Benzolamide increased the glutamate-evoked alkaline shifts by $42 \pm 37$ versus $320 \pm 71 \%(n=6)$ in PI-PLC-treated versus control slices, respectively ( $p<0.001$, unpaired $t$ test).

\section{Carbonic anhydrase activity of incubation fluids}

CA activity was present in incubation fluids from both control and PI-PLC-treated slices. In the PI-PLC-containing samples the acceleration factor for $\mathrm{CO}_{2}$ hydration was $1.80 \pm 0.13$ as compared with $1.27 \pm 0.06$ in control media $(n=12 ; p<0.01$; paired $t$ test).

Activity of CA II can be abolished completely by SDS (Whitney and Briggle, 1982; Brion et al., 1994b). CA IV, by contrast, is resistant to SDS, a feature attributed to its multiple disulfide linkages (Whitney and Briggle, 1982; Matsumura et al., 1989). When control and PI-PLC-containing incubation fluids were tested after a $30 \mathrm{~min}$ exposure to $0.2 \%$ SDS, the CA activity of the control fluid was eliminated in large part, whereas a sizable component of the activity usually remained in the PI-PLC-containing fluid. In the presence of SDS the mean acceleration factor of the control fluid was $1.08 \pm 0.03$, with a range from 0.99 to $1.18(n=6)$. The upper end of this range suggested that CA type IV was released in some control slices (see below). The incubation fluid from PI-PLCtreated slices, by contrast, had a mean acceleration factor of $1.27 \pm$ 0.07 (ranging from 1.05 to $1.41 ; n=6$ ), which was significantly different from the controls ( $p<0.05$, paired $t$ test). After the addition of the sulfonamide CA inhibitor methazolamide $(50 \mu \mathrm{M})$, the CA activity in control and PI-PLC-containing fluids became indistinguishable, with acceleration factors of $1.03 \pm 0.01$ versus $1.00 \pm 0.01$, respectively $(n=12 ; p>0.1$, paired $t$ test $)$.

\section{Western analysis of incubation fluid}

In two experiments the antisera to CA IV revealed a $39 \mathrm{kDa}$ band that was more abundant in samples obtained from PI-PLC-treated slices as compared with control fluid (Fig. 7, top). The standard run of human CA IV (50 ng) produced a band at $33 \mathrm{kDa}$. These migration patterns agree with earlier studies of rat (Waheed et al., 1992a,b) and mouse CA IV in comparison with the human enzyme (Brion et al., 1997). Normalizing the optical density (O.D.) of the human CA IV to 1.0, the control fluid yielded bands of 0.06 and 0.38. By contrast, the respectively paired O.D. of the PI-PLCtreated samples was 1.29 and 1.66 .

Staining for CA II revealed a $29 \mathrm{kDa}$ band in both control and PI-PLC-treated samples (Fig. 7, bottom). Although CA II was detected in samples from three of four animals, the degree of staining was variable, with near-absence of the enzyme in one sample pair. Reasons for this variability were not explored.

\section{Untreated Slice}

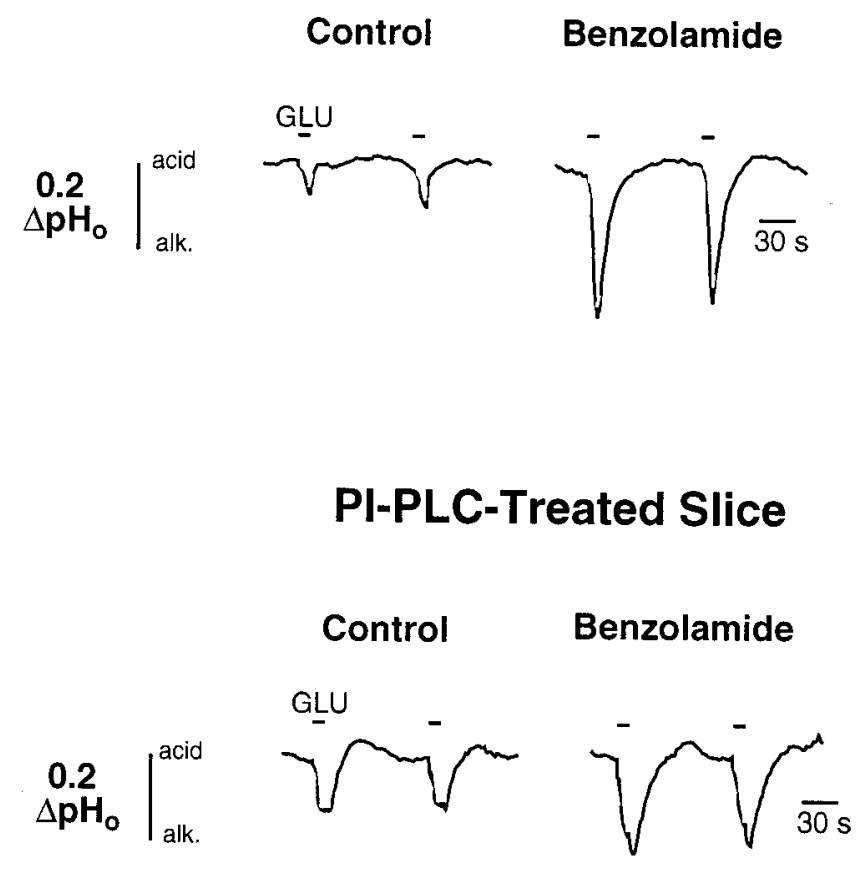

Figure 6. PI-PLC treatment precluded the effect of benzolamide on glutamate-evoked alkaline transients. Amplification of the alkaline shifts by benzolamide was reduced markedly in the PI-PLC-treated tissue. 

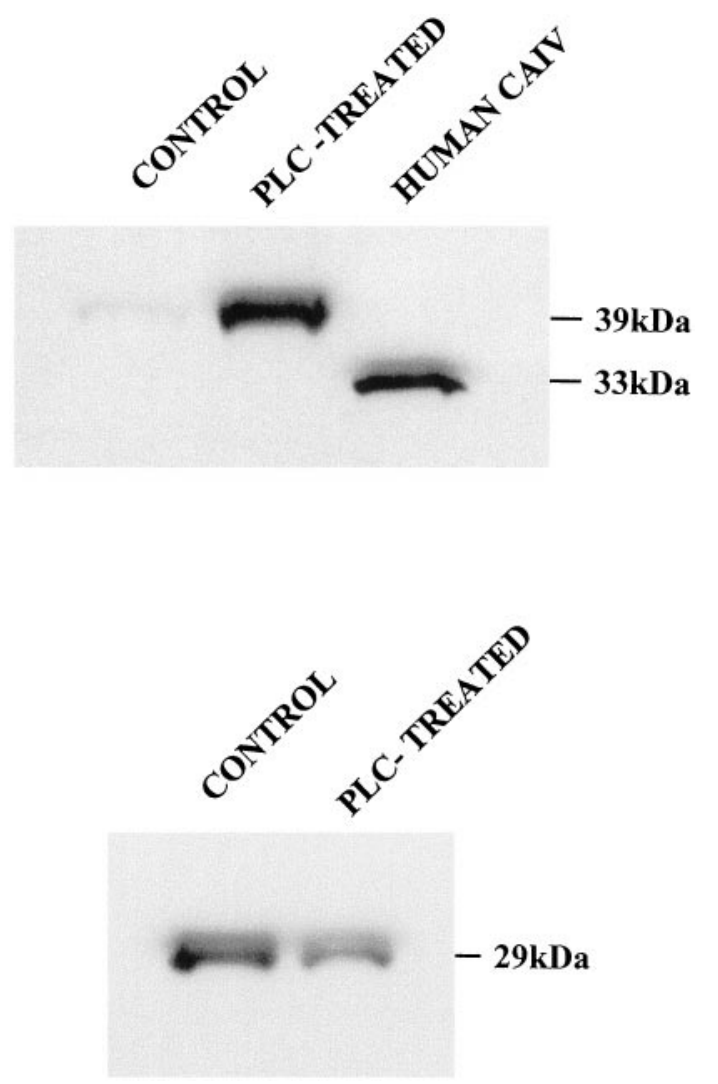

Figure 7. Western blot analysis of slice incubation fluid. Top, CA IV antisera. Incubation fluid from control slices showed a weak band migrating at $39 \mathrm{kDa}$ (O.D. of 0.06). Fluid from PI-PLC-treated slices showed a strong $39 \mathrm{kDa}$ band (O.D. of 1.29). Human CA IV migrated at $33 \mathrm{kDa}$ (normalized O.D. of 1.00). Bottom, CA II antisera. Fluid from both control and PI-PLCtreated slices contained CA II that migrated at $29 \mathrm{kDa}$.

\section{DISCUSSION}

The first evidence that CA can regulate activity-dependent changes in extracellular $\mathrm{pH}$ dates from the work of Kraig and colleagues (1983). In these studies the alkaline transients were amplified when acetazolamide was superfused over the rat cerebellar cortex. Later experiments that used impermeant CA inhibitors demonstrated that this CA activity was extracellular (Chen and Chesler, 1992a,b; Kaila et al., 1992). In view of the abundance of CA II within glia (Cammer, 1984; Cammer and Tansey, 1988) and the low concentration of extracellular enzyme (Huang et al., 1995), its release from glia has seemed a plausible explanation for extracellular activity. However, in brain slices from mutant mice lacking CA II, interstitial CA activity was no different from that of normal littermates (Tong et al., 2000). These observations suggested that CA II was not the interstitial CA.

The present study demonstrates that the brain interstitial CA activity is attributable to membrane-bound CA IV. Several lines of evidence support this claim. Much of the extracellular CA activity was abolished in brain slices that were treated with PI-PLC. This was evident as an increased amplitude of alkaline transients, whether evoked artificially (by $\mathrm{OH}^{-}$injection) or endogenously (by glutamate iontophoresis). A corollary observation was the diminished effect of benzolamide in the PI-PLC-treated slices: the amplification of alkaline shifts normally expected of this CA inhibitor was reduced in large part. The small effect of benzolamide that remained in the PI-PLC-treated slices could have been attributable to incomplete liberation of membrane-bound enzyme or to small amounts of CA II in the interstitial compartment (see below).

These results indicated that the interstitial CA activity was attributable to a CA isoform bound to the plasma membrane by a phosphatidylinositol-glycan linkage. The active CA isoforms asso- ciated with the plasma membrane include CA IV, CA IX, CA XII, and CA XIV (Fujikawa-Adachi et al., 1999; Mori et al., 1999). Among these, only CA IV is bound by a phosphatidylinositolglycan tether (Zhu and Sly, 1990; Ghandour et al., 1992).

With cleavage of CA IV from the plasma membrane, the enzyme would be expected to appear in the incubation media. Our studies demonstrated CA activity in the incubation fluid from both the PI-PLC-treated and the control slices. The total activity in both fluids was extremely low. Nonetheless, differences in the CA activity of the two fluids were evident. Most compelling was the differential sensitivity to SDS. Whereas exposure to SDS denatures CA II and abolishes its activity, CA IV is resistant to SDS, a feature attributed to its disulfide bridges (Whitney and Briggle, 1982; Matsumura et al., 1989). In control fluid the detectable CA activity was abolished in large part by SDS, whereas an SDS-resistant component remained in the PI-PLC-containing fluid, suggesting the presence of CA IV.

Western blots of control and PI-PLC-treated samples indicated the presence of both CA II and CA IV. Most significant was the far stronger staining for CA IV in the PI-PLC-treated samples. Barring the possibility of an immunologically cross-reactive CA isoform with SDS resistance and a similar phosphatidylinositol linkage, these results confirm that the interstitial CA of brain is CA IV. The release of CA IV from some control slices might be related to the leakage of endogenous lipases from injured cells.

Because CA II was present in the incubation fluid from both control and PI-PLC-treated slices, the degree to which CA II contributes to interstitial CA activity should be considered. Comparisons of CA activity in the samples indicated a greater total enzyme concentration in the PI-PLC-treated fluid. The acceleration of $\mathrm{CO}_{2}$ hydration by the samples was given by factors of 1.27 versus 1.80 in control and PI-PLC-treated samples, respectively. These modest accelerations correspond to very low levels of enzyme and cannot be related directly to concentrations. If the relationship for commercial bovine CA II were considered by example, the acceleration factors would correspond to enzyme concentrations of $\sim 8$ and $13 \mathrm{~nm}$, respectively. This estimate may be roughly applicable to the incubation fluids, because the turnover rates and activities of CA II and CA IV are similar (Maren et al., 1993). If one assumed that all of the detected activity was attributable to CA II and CA IV, the estimate would indicate similar concentrations of these enzymes in the incubation media.

Although the sample concentrations of CA II and CA IV were probably similar, the relative interstitial concentrations of these enzymes may have differed. Assuming all of the CA IV in the incubation fluid originated in the brain slice extracellular space and was released only once via the action of phospholipase, one may estimate its average interstitial concentration. Thus, if the assayed fluid contained $8 \mathrm{~nm} \mathrm{CA} \mathrm{IV} \mathrm{(estimated} \mathrm{from} \mathrm{an} \mathrm{acceleration} \mathrm{factor}$ of 1.27), then the total enzyme in the $50 \mu$ l of assay solution would amount to $4 \times 10^{-13} \mathrm{~mol}$ (representing the entire CA IV in the original incubation media). This quantity of enzyme was obtained from two slices, with an approximate combined slice volume of $1.5 \times 10^{-5} 1$. If the extracellular volume fraction had been $20 \%$, then $3 \times 10^{-6} 1$ would have contained $4 \times 10^{-13} \mathrm{~mol}$ of CA IV, corresponding to an interstitial concentration of $130 \mathrm{~nm}$. A somewhat higher figure would be expected if there had been incomplete cleavage of the CA IV from cell membranes. In a previous investigation in which the buffering effect of exogenous CA was studied, the estimate of interstitial CA concentration was of similar magnitude (Huang et al., 1995).

One may assume that CA II is leaking continuously from cells into the interstitial space, which is in slow equilibrium with the incubation fluid. Given equal accumulations of CA II and CA IV in the incubation fluid, $4 \times 10^{-13}$ mol of CA II would have been present in $\sim 150 \mu \mathrm{l}$ of fluid, representing a CA II concentration of only 2-3 nM. If there had been equilibrium between the bath and the extracellular space of the slice, then the interstitium also would have had a CA II concentration of 2-3 nM. The presence of CA II in the incubation fluid might represent an artifact of the brain slice, 
arising from damaged or dying cells. The variable detection of CA II on Western blots is consistent with this interpretation.

The extracellular localization of CA IV is not clear. Brain endothelial cells have been shown to express CA IV on their luminal membrane (Ghandour et al., 1992). The participation of this enzyme in interstitial buffering has not been excluded. However, the capillary enzyme is located some distance from sites of interstitial buffering and is separated from those sites by the bloodbrain barrier. Thus, the means by which this enzyme could catalyze interstitial buffering is not apparent.

Immunocytochemical and histochemical stains have not demonstrated a definitive interstitial CA in brain (Nogradi and Mihaly, 1988; Ghandour et al., 1992). Lack of distinct extracellular staining might be explained by a low concentration of interstitial enzyme. Indeed, in pyramidal neurons immuno- and histochemical stains do not reveal intracellular CA, although the cytoplasmic enzyme can be demonstrated by physiological methods (Pasternack et al., 1993).

The physiological studies that have demonstrated activity of $\mathrm{CA}$ in the brain interstitium have provided little information about the extracellular localization of the enzyme. Some evidence suggests that the extracellular CA is associated with glial cells. Interstitial CA activity was apparent in gliotic brain slices nominally devoid of neurons (Grichtchenko and Chesler, 1994). In addition, surface CA activity has been detected on dissociated retinal Muller cells (Newman, 1996). Whether CA is associated with neuronal membranes has not been addressed.

In summary, the present study provides compelling evidence that the interstitial CA in brain is attributable to membranebound CA IV. These results indicate that interstitial CA activity is a normal feature of the brain extracellular space and is not an artifact of injury. An apparent function of the enzyme is the regulation of activity-dependent $\mathrm{pH}$ shifts, particularly rapid alkaline transients. These alkalizations may influence normal synaptic transmission (Taira et al., 1993; Gottfried and Chesler, 1994) and pathological events such as seizure (Taira et al., 1993) and spreading depression (Tong and Chesler, 1999). Alkaline shifts augmented by CA inhibitors have been noted in species as diverse as leech (Rose and Deitmer, 1995) and rat (Kraig et al., 1983; Chen and Chesler, 1992a). Interstitial CA is therefore likely to be an early evolved, widespread feature of nervous systems.

\section{REFERENCES}

Brion LP, Zavilowitz BJ, Suarez C, Schwartz GJ (1994a) Metabolic acidosis stimulates carbonic anhydrase activity in rabbit proximal tubule and medullary collecting duct. Am J Physiol 266:F185-F195.

Brion LP, Suarez C, Zhang H, Cammer W (1994b) Up-regulation of carbonic anhydrase isozyme IV in CNS myelin of mice genetically deficient in carbonic anhydrase II. J Neurochem 63:360-366.

Brion LP, Cammer W, Satlin LM, Suarez C, Zavilowitz BJ, Schuster VL (1997) Expression of carbonic anhydrase IV in carbonic anhydrase II-deficient mice. Am J Physiol 273:F234-F245.

Bruns W, Gros G (1991) Modified micromethod for assay of carbonic anhydrase activity. In: The carbonic anhydrases (Dodgson S, Tashia R, Gros G, Carter N, eds), pp 127-131. New York: Plenum.

Cammer W (1984) Carbonic anhydrase in oligodendrocytes and myelin in the central nervous system. Ann N Y Acad Sci 429:494-497.

Cammer W, Tansey FA (1988) Carbonic anhydrase immunostaining in astrocytes in the rat cerebral cortex. J Neurochem 50:319-322.

Cammer W, Zhang H (1991) Comparison of immunocytochemical staining of astrocytes, oligodendrocytes, and myelinated fibers in the brains of carbonic anhydrase II-deficient mice and normal littermates J Neuroimmunol 34:81-86.

Carter ND, Fryer A, Grant AG, Hume R, Strange RG, Wistrand PJ (1990) Membrane-specific carbonic anhydrase (CAIV) expression in human tissues. Biochim Biophys Acta 1026:113-116.

Chen JCT, Chesler M (1992a) Modulation of extracellular pH by glutamate and GABA in rat hippocampal slices. J Neurophysiol 67:29-36.

Chen JCT, Chesler M (1992b) pH transients evoked by excitatory synaptic transmission are increased by inhibition of extracellular carbonic anhydrase. Proc Natl Acad Sci USA 89:7786-7790.

Chesler M (1990) The regulation and modulation of $\mathrm{pH}$ in the nervous system. Prog Neurobiol 34:401-427.
Chesler M, Chan CY (1988) Stimulus-induced extracellular pH transients in the in vitro turtle cerebellum. Neuroscience 27:941-948.

Chesler M, Kaila K (1992) Modulation of $\mathrm{pH}$ by neuronal activity. Trends Neurosci 15:396-402.

Chesler M, Rice ME (1991) Extracellular alkaline-acid pH shifts evoked by iontophoresis of glutamate and aspartate in turtle cerebellum. Neuroscience 41:257-267.

Dietzel I, Heinemann U, Hofmeier G, Lux HD (1980) Transient changes in the size of the extracellular space in the sensorimotor cortex of cats in relation to stimulus-induced changes in potassium concentration. Exp Brain Res 40:432-439.

Fujikawa-Adachi K, Nishimori I, Taguchi T, Onishi S (1999) Human carbonic anhydrase XIV (CA14): cDNA cloning, mRNA expression, and mapping to chromosome 1. Genomics 61:74-81.

Ghandour MS, Langley OK, Zhu XL, Waheed A, Sly WS (1992) Carbonic anhydrase IV on brain capillary endothelial cells: a marker associated with the blood-brain barrier. Proc Natl Acad Sci USA 89:6823-6827.

Gottfried JA, Chesler M (1994) Endogenous $\mathrm{H}^{+}$modulation of NMDA receptor-mediated EPSCs revealed by carbonic anhydrase inhibition in rat hippocampus. J Physiol (Lond) 478:373-378.

Grichtchenko I, Chesler M (1994) Depolarization-induced acid secretion in gliotic hippocampal slices. Neuroscience 62:1057-1070.

Grichtchenko I, Chesler M (1996) Calcium and barium-dependent extracellular alkaline shifts evoked by electrical activity in rat hippocampal slices. Neuroscience 75:1117-1126.

Huang W, Smith SE, Chesler M (1995) Addition of carbonic anhydrase augments extracellular $\mathrm{pH}$ buffering in rat cerebral cortex. J Neurophysiol 74:1806-1809.

Kaila K, Paalasmaa P, Taira T, Voipio J (1992) pH transients due to monosynaptic activation of $\mathrm{GABA}_{\mathrm{A}}$ receptors in rat hippocampal slices. NeuroReport 3:105-108.

Kraig RP, Ferreira-Filho CR, Nicholson C (1983) Alkaline and acid transients in cerebellar microenvironment. J Neurophysiol 49:831-850.

Lux HD (1974) Fast recording ion-specific microelectrodes: their use in pharmacological studies in the CNS. Neuropharmacology 13:509-517.

Maren TH (1967) Carbonic anhydrase: chemistry, physiology, and inhibition. Physiol Rev 47:595-781.

Maren TH, Wynns GC, Wistrand PJ (1993) Chemical properties of carbonic anhydrase IV, the membrane-bound enzyme. Mol Pharmacol 44:901-905.

Matsumura M, Signor G, Matthews BW (1989) Substantial increase of protein stability by multiple disulfide bonds. Nature 342:291-293.

Mori K, Ogawa Y, Ebihara K, Tamura N, Tashiro K, Kuwahara T, Mukoyama M, Sugawara A, Ozaki S, Tanaka I, Nakao K (1999) Isolation and characterization of CA XIV, a novel membrane-bound carbonic anhydrase from mouse kidney. J Biol Chem 274:15701-15705.

Newman EA (1996) Acid efflux from retinal glial cells generated by sodium bicarbonate cotransport. J Neurosci 16:159-168.

Nicholson C, Phillips JM (1981) Ion diffusion modified by tortuosity and volume fraction in the extracellular microenvironment of the rat cerebellum. J Physiol (Lond) 321:225-257.

Nogradi A, Mihaly A (1988) Distribution of carbonic anhydrase activity in the rat central nervous system, as revealed by a new semipermeable technique. Acta Histochem 84:153-162.

Paalasmaa P, Taira T, Voipio J, Kaila K (1994) Extracellular alkaline transients mediated by glutamate receptors in the rat hippocampal slice are not due to a proton conductance. J Neurophysiol 72:2031-2033.

Pasternack M, Voipio J, Kaila K (1993) Intracellular carbonic anhydrase activity and its role in GABA-induced acidosis in isolated rat hippocampal pyramidal neurones. Acta Physiol Scand 148:229-231.

Rose C, Deitmer J (1995) Stimulus-evoked changes of extra and intracellular $\mathrm{pH}$ in the leech central nervous system. II. Mechanisms and maintenance of $\mathrm{pH}$ homeostasis. J Neurophysiol 73:132-140.

Smith SE, Chesler M (1999) Effect of divalent cations on AMPAevoked alkaline shifts in rat hippocampal slices. J Neurophysiol 82:1902-1908.

Smith SE, Gottfried JA, Chen JCT, Chesler M (1994) Calcium dependence of glutamate receptor-evoked alkaline shifts in hippocampus. NeuroReport 5:2441-2445.

Taira T, Paalasmaa P, Voipio J, Kaila K (1995) Relative contributions of excitatory and inhibitory neuronal activity in alkaline transients evoked by stimulation of Schaffer collaterals in the rat hippocampal slice. J Neurophysiol 74:643-649.

Taira T, Smirnov S, Voipio J, Kaila K (1993) Intrinsic proton modulation of excitatory transmission in rat hippocampal slices. NeuroReport 4:93-96.

Tashian RE (1989) The carbonic anhydrases: widening perspectives on their evolution, expression, and function. BioEssays 10:186-192.

Tong C-K, Chesler M (1999) Endogenous pH shifts facilitate spreading depression by effect on NMDA receptors. J Neurophysiol 81:1988-1991. 
Tong CK, Cammer W, Chesler M (1999) Brain interstitial carbonic anhydrase is membrane-bound. Soc Neurosci Abstr 25:1507.

Tong CK, Cammer W, Chesler M (2000) Activity-dependent pH shifts in hippocampal slices from normal and carbonic anhydrase II-deficient mice. Glia 31:125-130.

Travis DM, Wiley C, Bohdan RN, Maren TH (1964) Selective renal carbonic anhydrase inhibition without respiratory effect: pharmacology of 2-benzenesulfonamido-1,3,4-thiadiazole-5-sulfonamide (CL 11,366). J Pharmacol Exp Ther 143:383-394.

Traynelis SF (1998) $\mathrm{pH}$ modulation of ligand-gated ion channels. In: pH and brain function (Kaila K, Ransom B, eds), pp 417-446. New York: Wiley-Liss

Waheed A, Zhu XL, Sly WS (1992a) Membrane-associated carbonic anhydrase from rat lung. Purification, characterization, tissue distri- bution, and comparison with carbonic anhydrase IVs of other mammals. J Biol Chem 267:3308-3311.

Waheed A, Zhu XL, Sly WS, Wetzel P, Gros G (1992b) Rat skeletal muscle membrane-associated carbonic anhydrase is $39 \mathrm{kDa}$ glycosylated GPI-anchored CA IV. Arch Biochem Biophys 294:550-556.

Waheed A, Okuyama T, Heyduk T, Sly WS (1996) Carbonic anhydrase IV: purification of a secretory form of the recombinant human enzyme and identification of the positions and importance of its disulfide bonds. Arch Biochem Biophys 333:432-438.

Whitney PL, Briggle TV (1982) Membrane-associated carbonic anhydrase purified from bovine lung. J Biol Chem 257:12056-12059.

Zhu XL, Sly WS (1990) Carbonic anhydrase IV from human lung. Purification, characterization, and comparison with membrane carbonic anhydrase from human kidney. J Biol Chem 265:8795-8801. 